\title{
Geostatistical Analysis on Spatial Variability of Soil Nutrients in Vertisols of Deccan Plateau Region of North Karnataka, India
}

\author{
Vinod Tamburi \\ Department of Civil Engineering, \\ National Institute of Technology Karnataka, Surathkal, India. \\ Corresponding author: vinodnayak2448@gmail.com \\ Amba Shetty \\ Department of Applied Mechanics and Hydraulics, \\ National Institute of Technology Karnataka, Surathkal, India. \\ E-mail: amba_shetty@yahoo.co.in \\ S. Shrihari \\ Department of Civil Engineering, \\ National Institute of Technology Karnataka, Surathkal, India. \\ E-mail: shrihari@nitk.edu.in
}

(Received August 13, 2019; Accepted December 6, 2019)

\begin{abstract}
Different methods of land use and management have a significant effect on soil properties distribution. Understanding of variations in soil nutrients in agricultural land use is important. An increase in extraction of nutrients, soil degradation, and management of nutrients is leading to a decline in quality of vertisols across the Deccan plateau of India. Though there are studies on spatial variability of vertisols macronutrients, studies on available calcium (Ca) and available magnesium $(\mathrm{Mg})$ are rare. This study is conducted in Gulbarga taluk, north Karnataka, India, to evaluate the variability of soil $\mathrm{pH}, \mathrm{Ca}, \mathrm{Mg}$, and Zinc (Zn). A total of 78 samples of soils are collected at 0 to $15 \mathrm{~cm}$ depth based on the accessibility and distribution of field patterns. Four subsamples represent a single composite sample. Agilent 4200 MP-AES (Microwave Plasma-Atomic. Emission Spectrometer) was used for determining the concentration of soil nutrients. The soil nutrients represent wide variation in coefficient of variation $(\mathrm{CV})$ with a value of $6 \%$ (for $\mathrm{pH}$ ) to $70.9 \%$ (for $\mathrm{Zn}$ ). The soil $\mathrm{pH}$ showed a significantly positive correlation to $\mathrm{Ca}$ and a negative correlation to $\mathrm{Mg}$. Geostatistical investigation indicates spherical model is the best fit for all nutrients. Except for $\mathrm{Ca}$, all nutrients showed moderate spatial dependence. Ordinary kriging is used to generate spatial variability maps. The maps of spatial variability are highly variable in nutrients content and indicate that site-specific management needs to be taken by local authorities and improve the livelihood of marginal farmers and also for sustainable agriculture.
\end{abstract}

Keywords- Vertisols, Geostatistics, Spatial variability, Soil nutrients.

\section{Introduction}

In the soil ecosystem, several components support the vegetation dependent on water and air. Soil composition is made up of organic matter, air, water, and nutrients (Panday et al., 2019). Healthy soil reduces agricultural requirements, pesticides, and fertilizers. Some of the factors affect the health of the soil, such as soil $\mathrm{pH}$, poor drainage, deficiencies in nutrients due to combined impact of physical, biological, and chemical processes over a period (Santra et al., 2008).

Different methods of land use and management have a substantial effect on soil properties, and understanding the variations in soil characteristics in agricultural land use is critical in determining soil nutrient limits. Soil properties differ in different spatial fields and may differ between crops or 
International Journal of Mathematical, Engineering and Management Sciences

Vol. 5, No. 2, 283-295, 2020

https://doi.org/10.33889/IJMEMS.2020.5.2.023

landscapes. Better soil quality is associated with agricultural sustainability with higher concentrations of soil organic matter and supply of essential nutrients.

Agricultural sustainability is the system's capability to maintain stable levels of production and long term quality without compromising both economic viability and the environment. It is alarming to find out that agricultural areas that contributed substantially to attaining the aim of self-sufficiency in production are now facing severe problems such as rapid depletion of nutrients.

To monitor soil health, it is essential to check the soil fertility status periodically. It is essential to assess the soil behavior and spatial variability of nutrients for agricultural practices. The prediction of spatial variability of secondary nutrients of the field is also vital for fertilizer and soil management. Spatial variability mapping plays an important role in site-specific management. Several studies have been conducted to study the spatial variability of soil nutrients in other parts of the globe (Laekemariam et al., 2018; Moharana et al., 2019; Panday et al., 2019).

India is classified into fifteen Agro-climatic zones based on soil patterns, climate, physiography, and cropping patterns (Venkateswarulu et al., 1996). Small farmlands, especially in the Deccan plateau, are prominent features for agriculture in India. About $80 \%$ of the farmers hold approximately two hectares, which accounts for $>50 \%$ of agricultural production. The average size of agricultural land ownership decreased from 2.3 ha in 1970 to 1.3 ha in 2000, with 0.32 hectares per capita in 2001 (Mythili and Goedecke, 2016). These small farms create serious financial pressures for farmers. Due to this stress, the use of green fertilizers or soil conservation facilities is restricted by labor, land, and capital resources (Bhattacharyya et al., 2015).

As a direct source of degradation, land scarcity, and poverty, as a whole, lead to unsustainable agricultural land management practices. The reason for the two other immediate causes of soil degradation are inadequate crop rotations and unbalanced use of fertilizers (Young, 1994). The use and practices of specific site management are strongly linked to the quality of soil. The implementation of adequate soil management procedures and planning the land use would be useful both to bring back the physicochemical quality of the degraded soil and to ensure consistent and sustainable soil conductivity (Panday et al., 2019). The specific site management is an alternative to traditional practices and cost-effective, which reduces the input of fertilizer application (Shaddad et al., 2019). The use of geostatistics improves the understanding of spatial dependence of soil nutrients, and kriging maps allow to assess the variability of soil nutrients (Lipiec and Usowicz, 2018).

In the Indian context, information on the available calcium status of soils is somewhat inadequate. About one-third of India's soil is covered with vertisols. A recent presentation of secondary nutrients barely mentions the extent of $\mathrm{Ca}$ and $\mathrm{Mg}$ deficiencies in India (Behera and Shukla, 2015). Due to the low base saturation, especially in areas with heavy precipitation, there may be a lack of $\mathrm{Ca}$ in many vertisols. No mapping is made beyond the $\mathrm{pH}$ and macronutrients. Among the nutrients, $\mathrm{Ca}$ is the least explored in India. Like $\mathrm{Ca}$, deficiency of $\mathrm{Mg}$ can be a problem in leached vertisols under high rainfall. $\mathrm{Mg}$ can be leached out easily when compared to $\mathrm{Ca}$, making acidic soil (Behera and Shukla, 2015). Over the decades, there has been a decline in the micronutrients of soil, and fertilizers are applied excessively to look after the soil condition and to increase the yield of crops (Kumar and Babel, 2011). Among the micronutrients, $\mathrm{Zn}$ is the most important for soil and plants equally. Among all the micronutrients, $\mathrm{Zn}$ deficiency is the most widely spreading micronutrient disorder among different soils (Sharma et al., 2013). 
International Journal of Mathematical, Engineering and Management Sciences

Vol. 5, No. 2, 283-295, 2020

https://doi.org/10.33889/IJMEMS.2020.5.2.023

The need for spatial variability mapping is high in the Deccan plateau of India, as it is mostly covered with vertisols. If vertisols are well managed, then they are highly productive, so it becomes significant to know spatial variability of the nutrients. The rapid soil degradation is affecting the decline in soil fertility, and small scale farms are reducing the yield. Minimal research to map the spatial variability of soil nutrients has been carried out primarily on $\mathrm{Ca}$ and $\mathrm{Mg}$. The $\mathrm{Zn}$ is most important micronutrient that helps in the growth of crops mainly for pigeon pea and Jowar as they are significant crops of the Deccan plateau region. Hence, it is important to know the variations of $\mathrm{Zn}$. The primary objective of study is to characterize the variability of soil nutrients and map their spatial variability with geostatistics (ordinary kriging) and to recommend soil fertility management practices. This study is useful for local planners for the adoption of specific site management.

\section{Materials and Methods}

\subsection{Study Area}

The Gulbarga district (Kalaburagi) is known as "Pulse Bowl of Karnataka" due to its extensive cultivation of Pigeonpea in the state of Karnataka. The study region is located in Gulbarga taluk, which covers 18,380 ha of land (Figure 1). The elevation region varies between 404 and $458 \mathrm{~m}$. The study zone is a semi-arid environment with a yearly precipitation of $834 \mathrm{~mm}$. The temperature varies from $8^{\circ} \mathrm{C}$ in December to $45^{\circ} \mathrm{C}$ in May. Vertisols are dominant with a water retention capacity of 200-300 mm and are suitable for pigeonpea cultivation (Rao et al., 2013). Major crops in this region are pigeon pea, chickpea, jowar, and sugarcane.

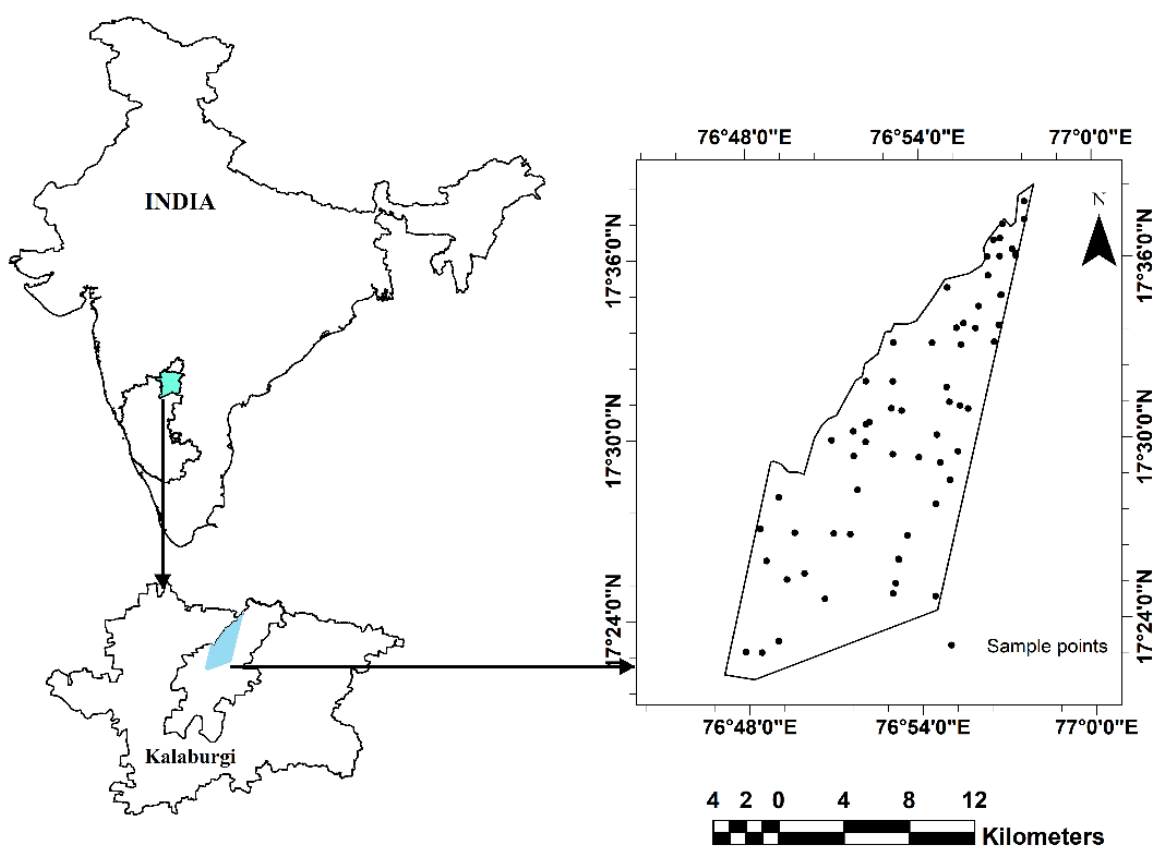

Figure 1. The location map of study area and sampling points 
International Journal of Mathematical, Engineering and Management Sciences

Vol. 5, No. 2, 283-295, 2020

https://doi.org/10.33889/IJMEMS.2020.5.2.023

\subsection{Soil Sampling and Analysis}

The samples of surface soil are collected from the study area using a soil auger in November 2016. This soil sampling duration is also coinciding with the passage of the Hyperion satellite over the study region. A total of 78 soil samples are collected according to dispersion of the fields. Four subsamples represent a soil sample.

The samples (Figure 1) are located by a global positioning system (GPS). Soil $\mathrm{pH}, \mathrm{Ca}, \mathrm{Mg}$, and $\mathrm{Zn}$ are measured using appropriate tests. Ammonium acetate extraction method for $\mathrm{Ca}$ and $\mathrm{Mg}$; the DTPA extraction method for $\mathrm{Zn}$ is used. The Agilent 4200 MP-AES is utilized to estimate concentration of soil nutrients (Vummiti, 2015). The permissible limits of $\mathrm{Ca}, \mathrm{Mg}$, and $\mathrm{Zn}$ are given in Table 1 (Kondi, 2016).

Table 1. The permissible limits of $\mathrm{pH}, \mathrm{Ca}, \mathrm{Mg}$, and $\mathrm{Zn}$

\begin{tabular}{cccc}
\hline Nutrient & Low & Medium & High \\
\hline $\mathrm{Ca}(\mathrm{meq} / 100 \mathrm{~g})$ & $<24.0$ & $24.0-32.0$ & $>32.0$ \\
$\mathrm{Mg}(\mathrm{meq} / 100 \mathrm{~g})$ & $<6.0$ & $6.0-8.0$ & $>8.0$ \\
$\mathrm{Zn}(\mathrm{ppm})$ & $<0.6$ & $0.6-1.5$ & $>1.5$ \\
\hline
\end{tabular}

\subsection{Classical Statistical Analysis}

The violin plots analyze the descriptive statistics as maximum, minimum, mean values of the entire set of the measured soil nutrients data. The normality test and the calculation of CV are carried out using the R and SPSS software, respectively. The violin plots allow us to analyze the density of datasets are aligned around the mean. A thin line which are outliers represents the distribution of rest datasets.

\subsection{Geostatistical Analysis}

The geostatistics interpolates the unsampled location values by kriging. Ordinary kriging is utilized for interpolating the values of unsampled location and generating spatial variability maps. (Goovaerts, 1998; Singh et al., 2010). For the interpolation of scatter point data, the semivariogram and the spatial variation are quantified by the information of the input data. Here, the spatial variability structure is evaluated by computing the variograms from Equation (1).

$\gamma(\mathrm{h})=\frac{1}{2 \mathrm{~N}(\mathrm{~h})} \sum_{\alpha=1}^{\mathrm{N}(\mathrm{h})}[\mathrm{z}(\mathrm{X} \alpha)-\mathrm{z}(\mathrm{X} \alpha+\mathrm{h})]^{2}$

Here, the number of sample pairs detached by range $h$ is represented by $\mathrm{N}$ and, $\mathrm{z}(\mathrm{X} \alpha)$ is the value of individual sample under the study region at $\alpha^{\text {th }}$ location.

The data should be normally distributed to minimize the effects of outliers for variogram and kriging assessment; therefore, soil nutrients data are evaluated for normal distribution using Q-Q plots. To normalize data distribution, log transformation is performed wherever it is needed (Goovaerts, 2001). Before the kriging, several semivariogram models are assessed to select the best fit with the dataset. The best fit model is selected on the adaptation of the semivariogram model closely fits the experimental values and exhibit minimum MSS error (mean sum of the square error) (Laekemariam et al., 2018). The values of MAE (mean absolute error) and root mean square error (RMSE) are computed. MAE is used to measure the proximity of the prediction to the outcomes 
International Journal of Mathematical, Engineering and Management Sciences

Vol. 5, No. 2, 283-295, 2020

https://doi.org/10.33889/IJMEMS.2020.5.2.023

(Equation 2), while RMSE represents the standard deviation of the differences between predicted and observed values(Equation 3) ( Reza et al., 2017). The best fit semivariogram model with the lowest MSS error is selected, and the results are used to calculate MAE and RMSE for individual soil nutrients.

$$
\begin{aligned}
& \text { MAE }=\frac{1}{\mathrm{~N}} \sum_{\alpha=1}^{\mathrm{N}} \mathrm{z}\left(\mathrm{x}_{\alpha}\right)-\bar{z}\left(\mathrm{x}_{\alpha}\right) \\
& \operatorname{RMSE}=\sqrt{\frac{\sum_{\alpha=1}^{\mathrm{N}}\left[\mathrm{z}\left(\mathrm{x}_{\alpha}\right)-\bar{z}\left(\mathrm{x}_{\alpha}\right)\right]^{2}}{\mathrm{~N}}}
\end{aligned}
$$

In above Equations (2) \& (3), $\mathrm{z}\left(\mathrm{x}_{\alpha}\right)$ represents the value of variable $\mathrm{z}$ at location $\mathrm{x}_{\alpha}$, the predicted value at $\alpha$ position is $\bar{z}\left(\mathrm{x}_{\alpha}\right)$, and the sample size is $\mathrm{N}$.

The nugget, sill, and range parameters are derived from best-fit models for recognizing spatial structure of the measured soil nutrients. The nugget is attributed to errors of measurement, or the spatial sources of variation at distances lower the sampling interval (Laekemariam et al., 2018). The sill represents total variance; the range represents a distance of separation, after which the measured data does not depend spatially. For classifying spatial dependence, the relationship between nugget to sill is considered a criterion (Cambardella et al., 1994). SpaceStat $4.0^{\circledR}$ software is used for analysis. The ordinary kriging is utilized for spatial interpolation as it is best suited to provide a balanced prediction for a specific unsampled location that reduces the variance error and makes the sum of the sample weights is equal to one (Lin and Chang, 2000).

\section{Results and Discussion}

\subsection{Descriptive Statistics and Geostatistics of Soil Nutrients}

The descriptive statistics of soil nutrients are tabulated in Table 2 and violin plots in Figure 2. The violin plot of $\mathrm{pH}$ indicates the density of data accumulated around the mean. It is noticeable that the study area is neutral, with a mean $\mathrm{pH}$ of 7.98 having the smallest coefficient of variation $(\mathrm{CV}=6 \%)$. Added to this, researchers have documented less variation in soil $\mathrm{pH}$ than other soil nutrients ( Reza et al., 2017; Shukla et al., 2017; Moharana et al., 2019). The reason for less variability was because the values of $\mathrm{pH}$ are logarithmic levels of concentration of the protons in soil solution unless the variability was greater (Reza et al., 2017). The $\mathrm{Ca}$ and $\mathrm{Mg}$ soil showed moderate variability (CV 25\% to 75\%) (Moharana et al., 2019), and violin plots also indicate the datasets are well distributed. $\mathrm{Zn}$ had the highest variability (CV-70.9\%) compared to other nutrients, the violin plot shows the outliers indicating at many regions the $\mathrm{Zn}$ is high. The application of secondary fertilizer $(\mathrm{Zn})$ to the soil, which leads to significant changes of $\mathrm{Zn}$ over small distances. $\mathrm{Ca}$ and $\mathrm{Mg}$ are moderate in variation due to the pedogenic process, as vertisols are formed by ingenious rocks (feldspar mineral), which contain $\mathrm{Ca}$ and $\mathrm{Mg}$. The variations in this area are for specific traditional farming practices by farmers and fertilizer applications(Shukla et al., 2017). 
International Journal of Mathematical, Engineering and Management Sciences

Vol. 5, No. 2, 283-295, 2020

https://doi.org/10.33889/IJMEMS.2020.5.2.023

Table 2. Soil nutrients descriptive statistics

\begin{tabular}{|c|c|c|c|c|c|c|c|}
\hline Soil Nutrients & Minimum & Maximum & Mean & Std.dev & $\mathrm{CV}(\%)$ & Kurtosis & Skewness \\
\hline $\mathrm{pH}$ & 6.52 & 8.82 & 7.98 & 0.481 & 6 & 0.590 & -0.997 \\
\hline $\mathrm{Ca}(\mathrm{meq} / 100 \mathrm{~g})$ & 18.67 & 79.09 & 43.82 & 11.783 & 26.8 & 0.697 & 0.585 \\
\hline $\mathrm{Mg}(\mathrm{meq} / 100 \mathrm{~g})$ & 5.3 & 44.19 & 20.43 & 9.348 & 45.7 & -0.631 & 0.505 \\
\hline $\mathrm{Zn}(\mathrm{ppm})$ & 0.22 & 11.0 & 1.98 & 1.410 & 70.9 & $4.21^{*}$ & $0.172^{*}$ \\
\hline
\end{tabular}
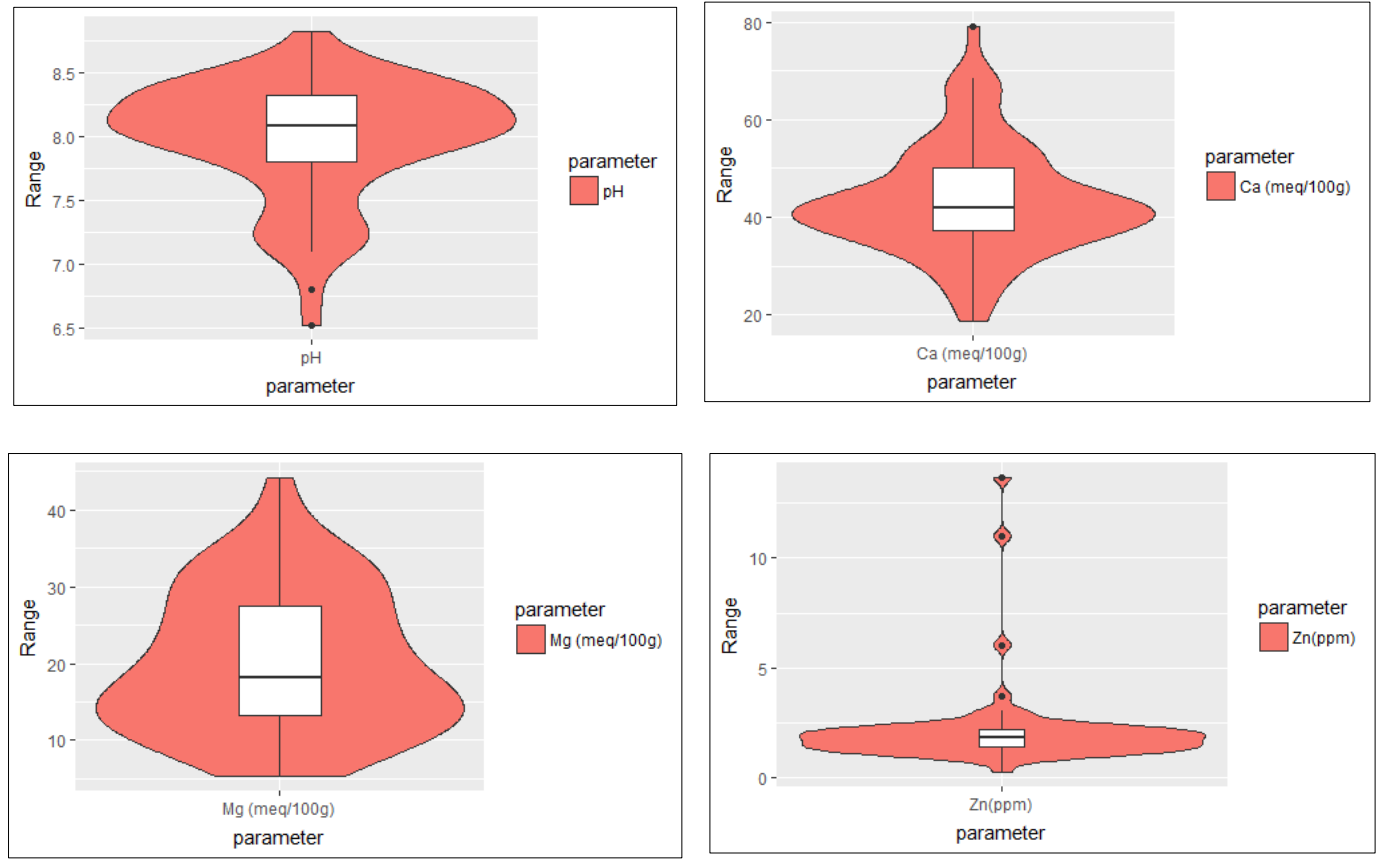

Figure 2. Violin plots for soil $\mathrm{pH}, \mathrm{Ca}, \mathrm{Mg}$ and $\mathrm{Zn}$

The Q-Q plots are plotted for raw data to observe the normal distribution of soil nutrients. Figure 3 shows that most of the nutrients are positively skewed except $\mathrm{pH}$ (figure not shown). As the data points not grouped adjacent to the diagonal line, the transformation of the data is done to reduce the effect of outliers. The log transformation adapted normality by reducing the skewness values. For $\mathrm{pH}$, the log transformation was not performed due to logarithmic proton concentration. After transformation, $\mathrm{Ca}$ and $\mathrm{Mg}$ showed no significant reduction in skewness. The skewness value of $\mathrm{Zn}$ has been reduced and can also be seen in the plot (Figure 3); the data points are clustered around the diagonal line after the transformation.

The Pearson linear correlation analysis was carried out to know the correlation between selected nutrients (Table 3 ). The soil $\mathrm{pH}$ correlated positively to Ca significantly $(\mathrm{r}=0.438, \mathrm{P}<0.01)$. An indication that the increase in $\mathrm{pH}$ gradually increases the $\mathrm{Ca}$ and vice versa, Iticha and Takele (2019) found a similar correlation in vertisols. The $\mathrm{pH}$ is negatively correlated to $\mathrm{Mg}$, and $\mathrm{Zn}$ is not 
International Journal of Mathematical, Engineering and Management Sciences

Vol. 5, No. 2, 283-295, 2020

https://doi.org/10.33889/IJMEMS.2020.5.2.023

as significant. The correlation between $\mathrm{Ca}$ and $\mathrm{Mg}$ is negative $(\mathrm{r}=-0.318, \mathrm{P}<0.01)$, results are contradictory to other soil types (Behera and Shukla, 2015; Iticha and Takele, 2019). The nutrients pairs, which are significantly negative correlated, are predictable to have spatial patterns that are mirror images (Corstanje et al., 2006).

The semi-variogram is calculated for finding the best model which describes the spatial structure in this area. Figure 4 represents the experimental semivariogram of soil nutrients that are best fitted, and Table 4 represents there results. The MSS error was found to be minimal corresponding to the spherical model for all soil nutrients and is therefore considered the most suitable model. Based on MSS error value, the best fit model was selected. It indicates the mean sum of square of differences between values of the variogram of the experimental and theoretical model that can be used to evaluate the influence of the variation of some of the factors.

The positive nugget indicated for soil nutrients, which is described as a result of short-range variability, sampling error, and intrinsic variability (Reza et al., 2016). The ratio of nugget to sill attributes to the degree of spatial structure to be Strong $(<25 \%)$, moderate $(25-75 \%)$, and weak (>75\%) spatial autocorrelation (Cambardella et al., 1994). Except for $\mathrm{Ca}$, which is weak, all soil nutrients have shown a moderate spatial dependence. Generally, spatial dependence is attributed to intrinsic factors of mineralogy and anthropogenic activities (Liu et al., 2006). In this region, the variability might be attributed to individual farming practices and fertilizer application rates.

The range is the separation by the distance between sample points, which are spatially autocorrelated. It is a distance upon which semivariance touches sill and then flattens out. The range is articulated as a distance, which is considered as diameter of the region of influence; it represents the maximum average distance at which the soil property has been correlated with two samples. The range of spatial variation to $\mathrm{pH}$ is $3347 \mathrm{~m}$ (Table 4), which is greater than $\mathrm{Ca}(\sim 1000 \mathrm{~m}), \mathrm{Mg}$ $(\sim 920 \mathrm{~m})$, and $\mathrm{Zn}(\sim 970 \mathrm{~m})$. Similar ranges for $\mathrm{Ca}$ and $\mathrm{Mg}$ are reported by Behera and Shukla (2015) for $\mathrm{pH}$ and $\mathrm{Zn}$, the ranges are different compared to Moharana et al. (2019) and Laekemariam et al., (2018). It indicates in this area, beyond this range, the soil nutrients are not spatial correlated. The greater the range recommends the more homogeneity of the soil within its scale. About variation in ranges of soil nutrients, Laekemariam et al. (2018) have compared various ranges, which are attributed to sampling intensities and study area size. They reported range varies because of the combined effect of agricultural practices, environmental conditions, and parental material. In our study area, the range is varied due to agricultural practices. From semivariogram analysis results, the Spherical model exhibited the best fit for selected nutrients. In accordance with the present results, the Spherical model is the best fit model for $\mathrm{pH}$ and $\mathrm{Ca}$ (Behera and Shukla, 2015; Laekemariam et al., 2018) and for Zn (Lin and Chang, 2000).

In general, the measured values must agree with predicted values; however, in certain conditions, data sets will scatter because of uncertainties and natural variations. The predictive performance datasets in the present study indicated good predictions. The MAE values for all the soil nutrients are near to zero, and RMSE near to zero are indications of good prediction (Omran, 2012; Laekemariam et al., 2018). 
International Journal of Mathematical, Engineering and Management Sciences

Vol. 5, No. 2, 283-295, 2020

https://doi.org/10.33889/IJMEMS.2020.5.2.023
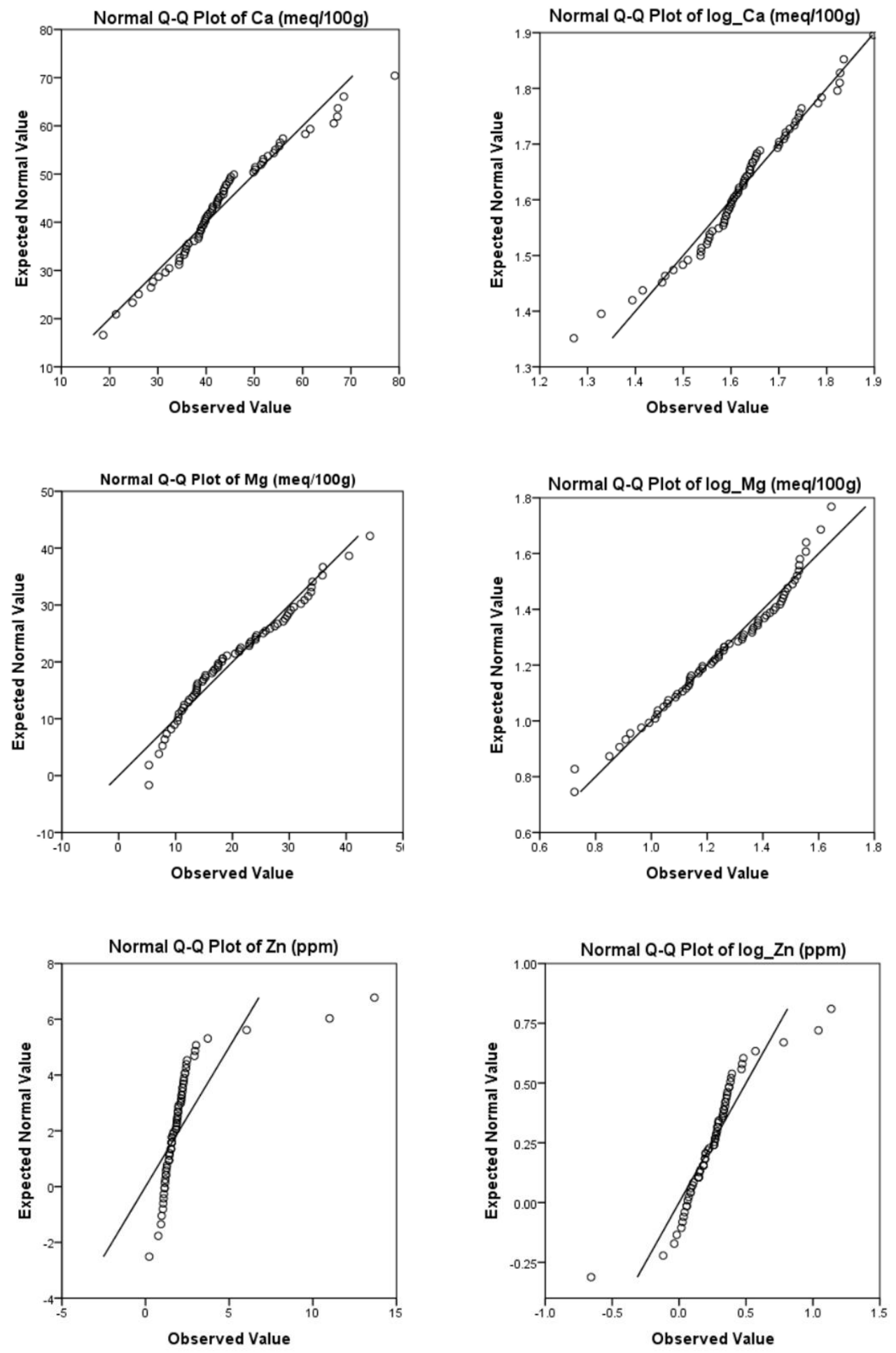

Figure 3. Q-Q plots for $\mathrm{Ca}, \mathrm{Mg}$, and $\mathrm{Zn}$ 
International Journal of Mathematical, Engineering and Management Sciences

Vol. 5, No. 2, 283-295, 2020

https://doi.org/10.33889/IJMEMS.2020.5.2.023

Table 3. Correlation between $\mathrm{pH}, \mathrm{Ca}, \mathrm{Mg}$ and $\mathrm{Zn}$

\begin{tabular}{|c|c|c|c|c|}
\hline & $\mathrm{pH}$ & $\begin{array}{c}\mathrm{Ca} \\
(\mathrm{meq} / 100 \mathrm{~g})\end{array}$ & $\begin{array}{c}\mathrm{Mg} \\
\text { (meq/100g) }\end{array}$ & $\begin{array}{c}\mathrm{Zn} \\
(\mathrm{ppm})\end{array}$ \\
\hline $\mathrm{pH}$ & 1 & & & \\
\hline $\mathrm{Ca}(\mathrm{meq} / 100 \mathrm{~g})$ & $0.438^{* * *}$ & 1 & & \\
\hline $\mathrm{Mg}(\mathrm{meq} / 100 \mathrm{~g})$ & -0.117 & $-0.318 * *$ & 1 & \\
\hline $\mathrm{Zn}(\mathrm{ppm})$ & -0.261 & -0.036 & 0.084 & 1 \\
\hline
\end{tabular}
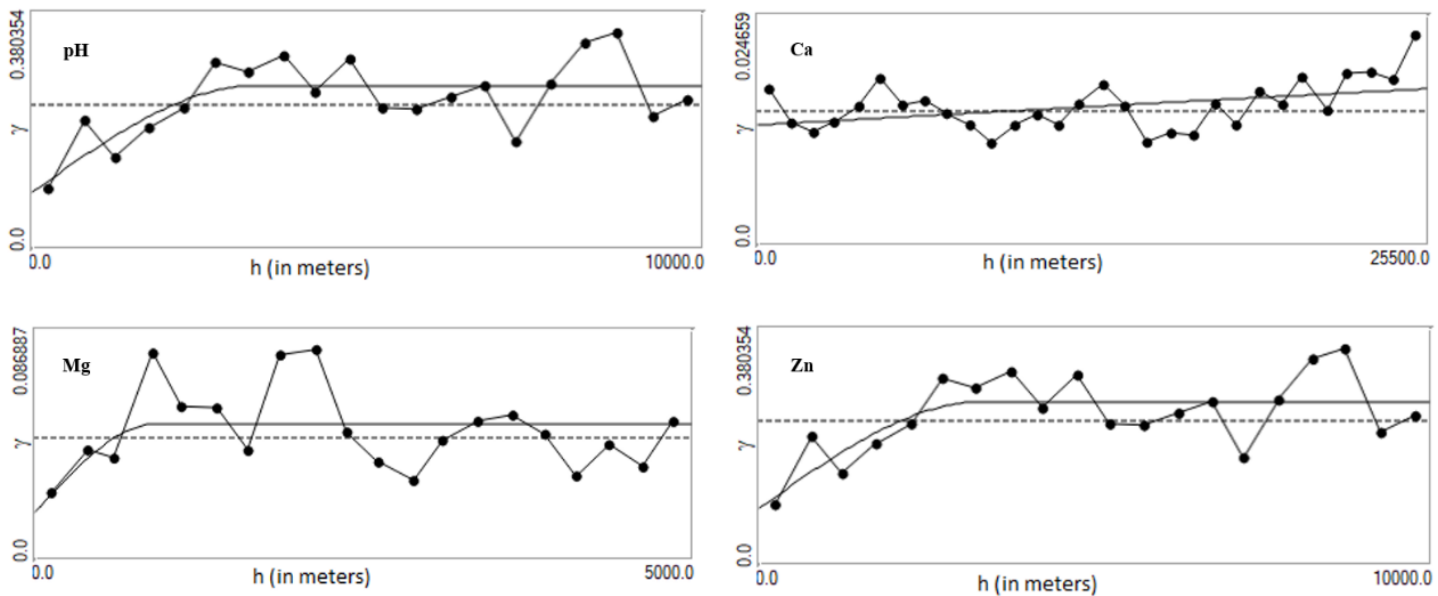

Figure 4. Semivariogram for soil $\mathrm{pH}, \mathrm{Ca}, \mathrm{Mg}$ and $\mathrm{Zn}$

Table 4. Semivariogram parameters for soil $\mathrm{pH}, \mathrm{Ca}, \mathrm{Mg}$ and $\mathrm{Zn}$

\begin{tabular}{|c|c|c|c|c|c|c|c|c|c|}
\hline \multirow[b]{2}{*}{ Soil Parameters } & \multicolumn{3}{|c|}{ Variogram parameter } & \multirow[b]{2}{*}{$\mathrm{N} / \mathrm{S}$} & \multirow[b]{2}{*}{ SD } & \multirow[b]{2}{*}{ MSSE } & \multirow[b]{2}{*}{ Model } & \multirow[b]{2}{*}{ MAE } & \multirow[b]{2}{*}{ RMSE } \\
\hline & $\begin{array}{c}\text { Range } \\
(\mathrm{m})\end{array}$ & Sill & Nugget & & & & & & \\
\hline $\mathrm{pH}$ & 3347.84 & 0.1721 & 0.0895 & 0.52 & moderate & 0.3200 & Spherical & 0.34 & 0.96 \\
\hline $\mathrm{Ca}$ (in meq/per100 g ) & 1002.21 & 0.0104 & 0.0128 & 1.23 & weak & 0.3320 & Spherical & 0.08 & 0.97 \\
\hline $\mathrm{Mg}$ (in meq/per100 $\mathrm{g}$ & 923.53 & 0.0335 & 0.0176 & 0.52 & moderate & 0.6299 & Spherical & 0.17 & 0.98 \\
\hline $\mathrm{Zn}$ (in ppm) & 974.77 & 0.0385 & 0.0113 & 0.29 & moderate & 0.6550 & Spherical & 0.14 & 1.01 \\
\hline
\end{tabular}

N: nugget; S: sill; SD: spatial dependence; MSSE: mean sum of the square error; RMSE: root mean squared error; MAE: mean absolute error

\subsection{Spatial Variability Maps}

The maps of spatial variability of the nutrients generated by ordinary kriging, which gives information about nutrients variability. Ordinary kriging provides an unbiased prediction for unsampled positions since it minimizes variance error (Liu et al., 2014). The search strategy used for generating the maps are five closest neighbors to define the spatial weight, non-stratified search type with sixteen maximum number of observations, and euclidian distance for selecting neighbors are used. These maps of spatial variability are of great benefit for site-specific planning and cultivation (Figure 5). 

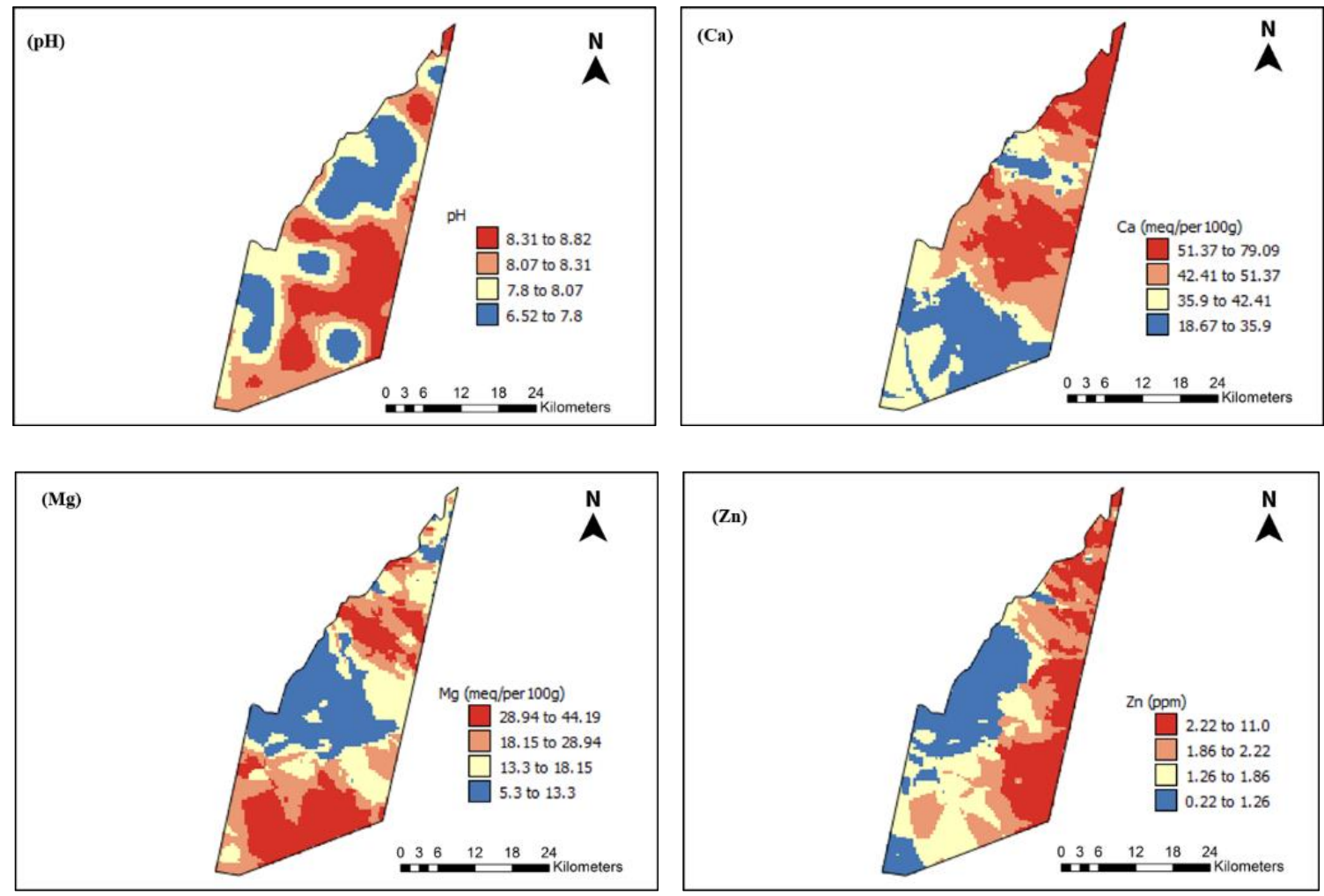

Figure 5. Spatial variability maps of soil $\mathrm{pH}, \mathrm{Ca}, \mathrm{Mg}$ and $\mathrm{Zn}$

The $\mathrm{pH}$ of the soil is ranging from alkaline to neutral in the study area; towards the southern part, it is alkaline, which is not preferable for crops. $\mathrm{Ca}$ and $\mathrm{Mg}$ are negatively correlated (Table 3). The maps of spatial variability also indicate in a similar way as the region in which $\mathrm{Ca}$ is low has shown a relatively high presence of $\mathrm{Mg}$. The $\mathrm{Ca}$ is on higher ranges, as well as $\mathrm{Mg}$ (Table 1). The presence of higher ranges of $\mathrm{Ca}$ and $\mathrm{Mg}$ in this region may be due to vertisols formation from basalt rocks along with agricultural practices. $\mathrm{Zn}$ is relatively higher towards the south-east and north-east of the study region (Table 1), the productivity is reduced due to lower $\mathrm{Zn}$ content. The possible reason for $\mathrm{Zn}$ variability could be unsuitable fertilizer applications and unfavorable soil $\mathrm{pH}$ (Panday et al., 2019). According to our findings, the vertisols are homogeneous, but individual farming practices and fertilizer application rates are making heterogeneous. So, the traditional practices of farmers must include site-specific soil management. The usability of these variability maps should be increased at a regional scale, and farmers should know the characteristics associated with the exploration of spatial variability of soil nutrients in their respective fields.

\section{Conclusions}

The present study revealed Soil $\mathrm{pH}, \mathrm{Ca}, \mathrm{Mg}$, and $\mathrm{Zn}$ varied widely in vertisols of Gulbarga Taluk of Karnataka, India. Soil $\mathrm{pH}$ is positively correlated to $\mathrm{Ca}$ and $\mathrm{Ca}$ is negatively correlated significantly to $\mathrm{Mg}$, except $\mathrm{Ca}$ all nutrients showed moderately spatial dependency. The spatial dependence is varied nearly up to one-kilometer range. The ranges obtained will be helpful for other researchers while sampling. The spatial variability maps have large variability. According to 
International Journal of Mathematical, Engineering and Management Sciences

Vol. 5, No. 2, 283-295, 2020

https://doi.org/10.33889/IJMEMS.2020.5.2.023

our findings, the vertisols are homogeneous, but individual farming practices and fertilizer application rates are making heterogeneous. These maps are helpful to local authorities for taking site-specific management decisions. Hence the site-specific management decision for sustainable agriculture requires to be made to improve the livelihood of small farmers.

\section{Conflicts of Interest}

The authors declare no competing interests.

\section{Acknowledgments}

We acknowledge and express our gratitude to the Chief Scientist of BioMedware, Dr. Pierre Goovaerts, for his analytical assistance in SpaceStat Software. We thank the professor of the University of Horticultural Science Bagalkot, Dr. M.S. Nagaraja, for support in the laboratory.

\section{References}

Behera, S.K., \& Shukla, A.K. (2015). Spatial distribution of surface soil acidity, electrical conductivity, soil organic carbon content and exchangeable potassium, calcium and magnesium in some cropped acid soils of India. Land Degradation \& Development, 26(1), 71-79.

Bhattacharyya, R., Ghosh, B.N., Mishra, P.K., Mandal, B., Rao, C.S., Sarkar, D., Das, K., Anil, K.S., Lalitha, M., Hati, K.M., \& Franzluebbers, A.J. (2015). Soil degradation in India: challenges and potential solutions. Sustainability, 7(4), 3528-3570.

Cambardella, C.A., Moorman, T.B., Parkin, T.B., Karlen, D.L., Novak, J.M., Turco, R.F., \& Konopka, A.E. (1994). Field-scale variability of soil properties in central Iowa soils. Soil Science Society of America Journal, 58(5), 1501-1511.

Corstanje, R., Grunwald, S., Reddy, K.R., Osborne, T.Z., \& Newman, S. (2006). Assessment of the spatial distribution of soil properties in a northern everglades marsh. Journal of Environmental Quality, 35(3), 938-949.

Goovaerts, P. (1998). Geostatistical tools for characterizing the spatial variability of microbiological and physico-chemical soil properties. Biology and Fertility of Soils, 27(4), 315-334.

Goovaerts, P. (2001). Geostatistical modelling of uncertainty in soil science. Geoderma, 103(1-2), 3-26.

Iticha, B., \& Takele, C. (2019). Digital soil mapping for site-specific management of soils. Geoderma, 351, 85-91.

Kondi, A.E. (2016). Nutrient management practices in grape orchards of Bagalkot and Jamakhandi talukas: effects on soil fertility, petiole nutrient contents and yields. Doctoral dissertation, University of Horticultural Sciences, Bagalkot.

Kumar, M., \& Babel, A.L. (2011). Available micronutrient status and their relationship with soil properties of jhunjhunu tehsil, district Jhunjhunu, Rajasthan, India. Journal of Agricultural Science, 3(2), 97-106.

Laekemariam, F., Kibret, K., Mamo, T., \& Shiferaw, H. (2018). Accounting spatial variability of soil properties and mapping fertilizer types using geostatistics in southern Ethiopia. Communications in Soil Science and Plant Analysis, 49(1), 124-137.

Lin, Y.P., \& Chang, T.K. (2000). Geostatistical simulation and estimation of the spatial variability of soil zinc. Journal of Environmental Science and Health - Part A, 35(3), 327-347. 
International Journal of Mathematical, Engineering and Management Sciences

Vol. 5, No. 2, 283-295, 2020

https://doi.org/10.33889/IJMEMS.2020.5.2.023

Lipiec, J., \& Usowicz, B. (2018). Spatial relationships among cereal yields and selected soil physical and chemical properties. Science of the Total Environment, 633, 1579-1590.

Liu, D., Wang, Z., Zhang, B., Song, K., Li, X., Li, J., Li, F., \& Daun, H. (2006). Spatial distribution of soil organic carbon and analysis of related factors in croplands of the black soil region, Northeast China. Agriculture, Ecosystems \& Environment, 113(1-4), 73-81.

Liu, Z., Zhou, W., Shen, J., He, P., Lei, Q., \& Liang, G. (2014). A simple assessment on spatial variability of rice yield and selected soil chemical properties of paddy fields in South China. Geoderma, 235, 3947.

Moharana, P.C., Jena, R.K., Pradhan, U.K., Nogiya, M., Tailor, B.L., Singh, R.S., \& Singh, S.K. (2019). Geostatistical and fuzzy clustering approach for delineation of site-specific management zones and yield-limiting factors in irrigated hot arid environment of India. Precision Agriculture, 1-23. https://doi.org/10.1007/s11119-019-09671-9.

Mythili, G., \& Goedecke, J. (2016). Economics of land degradation in India. In: Economics of Land Degradation and Improvement- A Global Assessment for Sustainable Development. Springer International Publishing, Cham, pp. 431-469.

Omran, E.S.E. (2012). Improving the prediction auccuracy of soil mapping through geostatistics. International Journal of Geosciences, 3, 574-590.

Panday, D., Ojha, R.B., Chalise, D., Das, S., \& Twanabasu, B. (2019). Spatial variability of soil properties under different land use in the dang district of Nepal. Cogent Food \& Agriculture, 5(1), 1600460. https://doi.org/10.1080/23311932.

Rao, A.V.R.K., Wani, S.P., Srinivas, K., Singh, P., Bairagi, S.D., \& Ramadevi, O. (2013). Assessing impacts of projected climate on pigeonpea crop at Gulbarga. Journal of Agrometeorology, 15, 32-37.

Reza, S.K., Baruah, U., Sarkar, D., \& Singh, S.K. (2016). Spatial variability of soil properties using geostatistical method: a case study of lower Brahmaputra plains, India. Arabian Journal of Geosciences, 9(6), 446. https://doi.org/10.1007/s12517-016-2474-y.

Reza, S.K., Nayak, D.C., Mukhopadhyay, S., Chattopadhyay, T., \& Singh, S.K. (2017). Characterizing spatial variability of soil properties in alluvial soils of India using geostatistics and geographical information system. Archives of Agronomy and Soil Science, 63(11), 1489-1498.

Santra, P., Chopra, U.K., \& Chakraborty, D. (2008). Spatial variability of soil properties and its application in predicting surface map of hydraulic parameters in an agricultural farm. Current Science, 95(7), 937945.

Shaddad, S.M., Buttafuoco, G., Elrys, A., \& Castrignanò, A. (2019). Site-specific management of salt affected soils: a case study from Egypt. Science of the Total Environment, 688, 153-161.

Sharma, A., Patni, B., Shankhdhar, D., \& Shankhdhar, S.C. (2013). Zinc-an indispensable micronutrient. Physiology and Molecular Biology of Plants, 19(1), 11-20.

Shukla, A.K., Sinha, N.K., Tiwari, P.K., Prakash, C., Behera, S.K., Lenka, N.K., Singh, V.K., Dwivedi, B.S., Majumdar, K., Kumar, A., Srivastava, P.C., Pachauri, S.P., Meena, M.C., Lakaria, B.L., \& Siddiqui, S. (2017). Spatial distribution and management zones for sulphur and micronutrients in Shiwalik Himalayan Region of India. Land Degradation \& Development, 28(3), 959-969.

Singh, K.N., Rathore, A., Tripathi, A.K., Subba Rao, A., Khan, S., \& Mukherjee, S.P. (2010). Soil fertility manning and its validation using spatial prediction techniques. Journal of the Indian Society of Agricultural Statistics, 64, 359-365.

Venkateswarulu, J., Ramakrishna, Y.S., \& Rao, A.S. (1996). Agro-climatic zones of India. Annals of Arid Zone, 35(1), 1-7. 
International Journal of Mathematical, Engineering and Management Sciences

Vol. 5, No. 2, 283-295, 2020

https://doi.org/10.33889/IJMEMS.2020.5.2.023

Vummiti, D. (2015). Determination of available nutrients in soil using the Agilent 4200 MP-AES. Agilent Technologies, India.

Young, A. (1994). Land degradation in South Asia: its severity, causes, and effects upon the people. World Soil Resources Report 78, United Nations Development Programme, United Nations Environment Programme, Food and Agriculture Organization of the United Nations, $100 \mathrm{pp}$. 